\title{
Preparation of Polypyrrole/Polyethylene Composite Films by the Vapor-Phase Oxidative Polymerization of Pyrrole
}

\author{
Kouichirou KURACHI and Hideo KISE* \\ Institute of Materials Science, University of Tsukuba, Tsukuba, \\ Ibaraki 305, Japan
}

(Received April 8, 1994)

\begin{abstract}
Electrically conductive polypyrrole/polyethylene composite films were prepared by the vapor-phase polymerization of pyrrole on porous polyethylene films containing $\mathrm{FeCl}_{3}$ or $\mathrm{Fe}\left(\mathrm{ClO}_{4}\right)_{3}$ as oxidants. The conductivity of the composite films increased by lowering polymerization temperature. The conductivity of the composite films was also a strong function of the oxidation potential of oxidant solutions which were impregnated into the polyethylene films prior to the polymerization of pyrrole. Maximum conductivity was obtained using short chain alcohols as solvents. It was found that the composite films have excellent mechanical properties compared to polypyrrole.
\end{abstract}

KEY WORDS Polypyrrole / Polyethylene / Composite Film / Vapor-Phase Polymerization / Iron Chloride / Oxidation Potential / Mechanical Properties /

Interest is rapidly growing in the applications of electrically conductive polymers such as rechargeable batteries and electronic devices. However, there are some disadvantages in using conductive polymers because of their low mechanical properties and low stability against air oxidation. To overcome these drawbacks, the preparation of composites of conductive polymers with other polymer materials has been investigated. As for polypyrrole (PPy), composites with poly(vinyl chloride) (PVC), ${ }^{1-6}$ poly(vinyl alcohol) (PVA), ${ }^{7-10}$ polyacrylonitrile (PAN), ${ }^{11,12}$ or polyurethane ${ }^{13}$ have been prepared by either chemical or electrochemical methods.

It has been reported that the vapor-phase polymerization of pyrrole on a polymer material containing an oxidant is a facile and versatile method for the preparation of conductive composite materials; examples are composites of PPy with PVC, ${ }^{5}$ PVA, ${ }^{7,9}$ PAN,${ }^{11}$ polyurethane, ${ }^{13}$ and polyimide. ${ }^{14}$ Many processes for the preparation of these composites include the impregnation of an oxidant in the polymer material followed by vapor phase oxidative polymerization of pyrrole. Iron(III) chloride $\left(\mathrm{FeCl}_{3}\right)$ has been used most extensively as an oxidant. However, few reports have appeared on the composites of PPy with olefin (alkene) polymers such as polyethylene or polypropylene. Iron(III) chloride is not only an oxidant but also a strong Lewis acid, and it may react with polar groups in polymers such as PVC and PVA. To maintain the original mechanical properties of the matrix polymer, it may be desirable to employ inert polymers as matrix components of the composites with PPy. This paper describes the preparation of $\mathrm{PPy} /$ polyethyelen composite films by oxidative vapor-phase polymerization of pyrrole on $\mathrm{FeCl}$ - or $\mathrm{Fe}\left(\mathrm{ClO}_{4}\right)_{3}$-impregnated porous polyethylene films.

\section{EXPERIMENTAL}

\section{Materials \\ Pyrrole was obtained from Tokyo Kasei Kogyo Co., Ltd. and distilled before use.}


Iron(III) chloride and iron(III) perchlorate were obtained from Wako Pure Chemical Industries, Ltd. and used without further purification. Porous polyethylene (PE) films were kindly provided by Mitsubishi Kasei Co., Ltd. The average thickness and pore diameter of the films were $10-12 \mu \mathrm{m}$, and $0.03 \mu \mathrm{m}$, respectively, and the voids of the films were $60-70 \%$.

\section{Preparation of PPy/PE Composite Films}

Typically, a piece of PE film $(3 \mathrm{~cm} \times 3 \mathrm{~cm})$ was impregnated with a $0.5 \mathrm{M}$ solution of $\mathrm{FeCl}_{3}$ in methanol by dipping the film into the solution. After most of the solvent was evaporated in the air, the film was placed in a glass flask equipped with a dropping funnel.The polymerization of pyrrole was done under nitrogen stream by dropping pyrrole monomer into a glass vessel in the flask. The temperature of the flask was kept constant by a water bath equipped with a temperaturecontrolled water circulator. After the reaction, the $\mathrm{PPy} / \mathrm{PE}$ composite film was washed by acetone with ultrasonication and dried under vacuum.

\section{Measurements}

Electric conductivity along the surface of $\mathrm{PPy} / \mathrm{PE}$ films was measured by the four-probe method at $30^{\circ} \mathrm{C}$ under vacuum. The conductivity across the thickness of the film was calculated from the electrical resistance between the copper plates attached to the surfaces of the films by conductive paste.

The oxidation potential of $\mathrm{FeCl}_{3}$ solutions was measured against a standard calomel electrode (SCE) using a Hokuto Denko HA-501G potentiostat.

Infrared spectra were recorded on a JEOL JIR-100 spectrometer and scanning electron micrographs were taken with a JEOL JSM-840 microscope. The mechanical properties of the films were measured with a Shimadzu AGS$5 \mathrm{kNB}$ autograph.

\section{RESULTS AND DISCUSSION}

\section{Effects of Polymerization Temperature}

When a porous polyethylene (PE) film impregnated with $\mathrm{FeCl}_{3}$ or $\mathrm{Fe}\left(\mathrm{ClO}_{4}\right)_{3}$ was exposed to pyrrole vapor, coloration of the film occurred which indicated the formation of polypyrrole (PPy) on the surface of the film. As shown in Figure 1, the IR spectrum of the product has characteristic absorption bands of PPy at 1539, 1306, 1169, 1041, 893, and $779 \mathrm{~cm}^{-1} \cdot{ }^{15-17}$ In addition, the spectrum had a broad and strong band from 4000 to $1700 \mathrm{~cm}^{-1}$, probably the tail of an electronic absorption band in the near IR. ${ }^{15,18}$ The spectrum was exactly the sum of those of PPy and PE, and no structural changes in PE were detected. This suggests that $\mathrm{PE}$ is an inert polymer against $\mathrm{FeCl}_{3}$ which may possibly be a significant advantage of using PE as a matrix polymer for conducting composite materials by oxidative polymerization. The mechanical properties of PPy films were much improved by $\mathrm{PE}$.

It has been reported that the conductivity of PPy is strongly dependent on the polymerization temperature of pyrrole. ${ }^{19-21}$ Therefore, we first investigated the effects of polymerization temperature on the amount of PPy formed in the films and the conductivity of composite films. Although PPy/PE composite films should contain chloride ion as a counter ion of oxidize PPy (probably about $0.3 \mathrm{Cl}$ ion per pyrrole ring), ${ }^{15,21}$ it may be assumed that weight increase of the film reflects the amount of PPy formed. As Figure 2 shows, the weight of composite film increased with polymerization time, but after $24 \mathrm{~h}$, weight increase was independent of the reaction temperature except for the polymerization at $0^{\circ} \mathrm{C}$. In contrast, the conductivity of composite films obtained by $24 \mathrm{~h}$ reactions was significantly dependent on the reaction temperature; the lower the temperature, the higher the conductivity (Figure 3). That the polymerization temperature is a controlling factor of conductivity is 


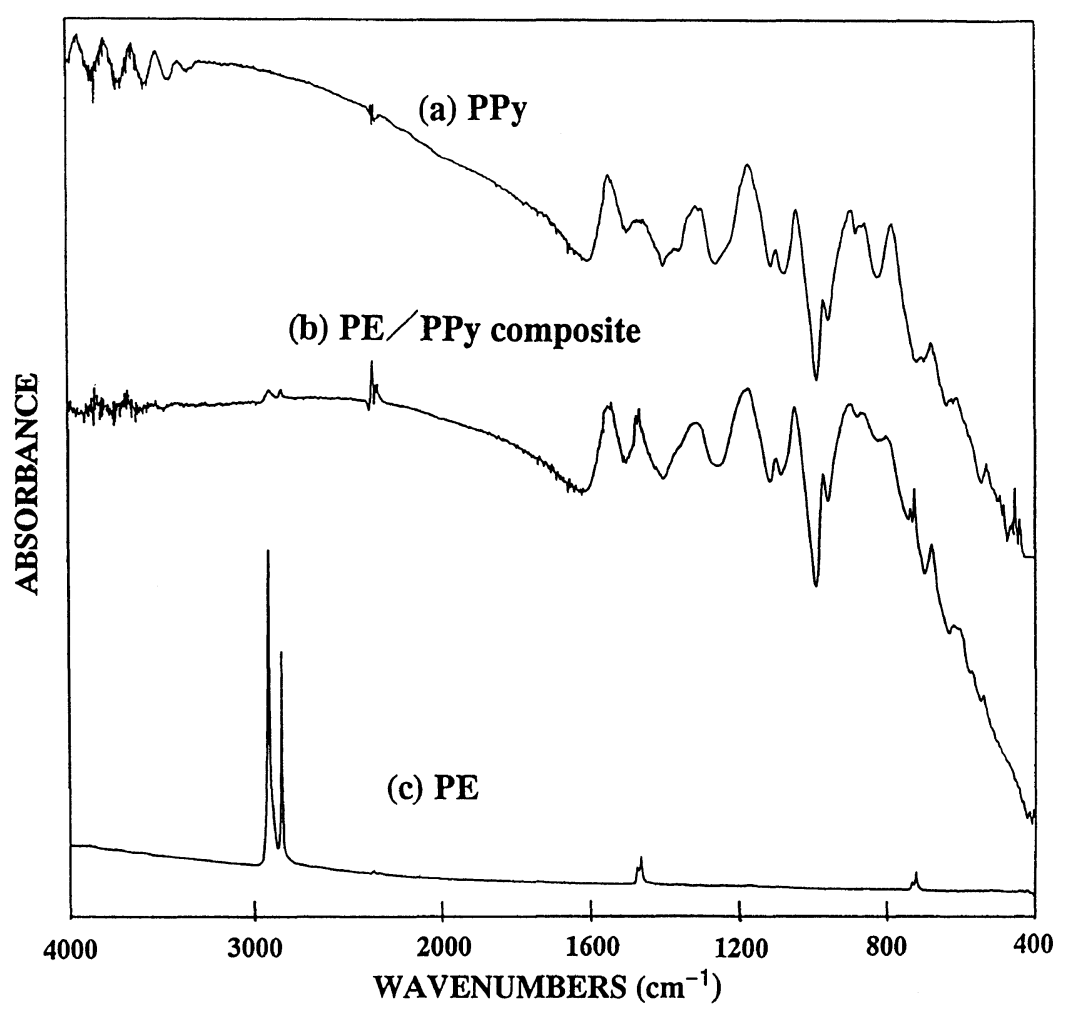

Figure 1. IR spectra of (a) PPy prepared by vapor-phase polymerization of pyrrole on the surface of an aqueous $\mathrm{FeCl}_{3}$ solution, (b) PPy/PE composite film, and (c) PE film.

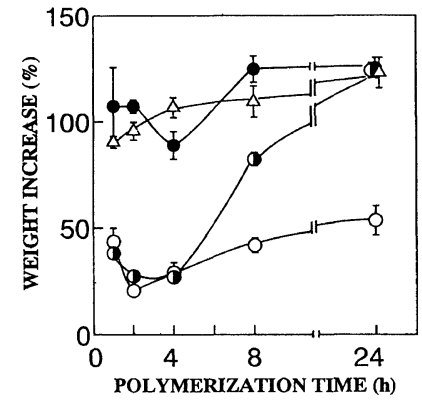

Figure 2. Weight increase of $\mathrm{PPy} / \mathrm{PE}$ films prepared by $\mathrm{FeCl}_{3}$-methanol. Polymerization temperatures, $\mathrm{O}, 0^{\circ} \mathrm{C}, \mathrm{O}$, $10^{\circ} \mathrm{C}, 0,25^{\circ} \mathrm{C}$, and $\triangle, 40^{\circ} \mathrm{C}$.

illustrated in Figure 4, in which conductivity is plotted against weight increase of the composites obtained at all the reaction times and temperatures investigated. It can be clearly seen that the composites of higher conductivity were always obtained at lower temperatures.

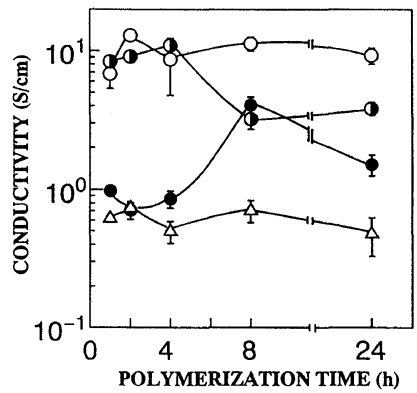

Figure 3. Conductivity of $\mathrm{PPy} / \mathrm{PE}$ films prepared by $\mathrm{FeCl}_{3}-$ methanol. Symbols are the same as in Figure 2.

The same was observed for polymerization with $\mathrm{Fe}\left(\mathrm{ClO}_{4}\right)_{3}$ as an oxidant (Figure 5).

It should be noted that, in this work, conductivity was calculated on the basis of total thickness of the composite films, and therefore, the conductivity of intrinsic PPy should be higher than calculated values. Film thickness 
was essentially independent of the polymerization temperature. Therefore, conductivity is considered to reflect that of PPy. The results shown in Figures 4 and 5 indicate that, in spite of smaller amounts of PPy in the composite films, the conductivity of the films obtained at lower temperatures is higher than those obtained at higher temperatures. This suggests that PPy formed at lower temperatures has

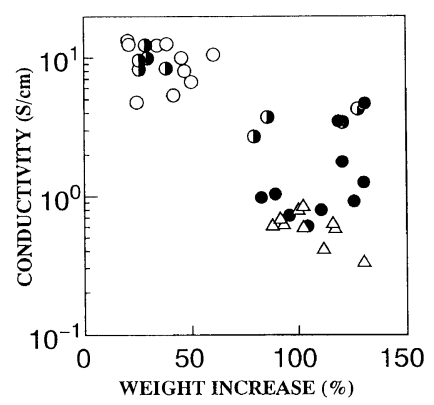

Figure 4. Plots of conductivity against weight increase of PPy-PE films prepared by $\mathrm{FeCl}_{3}-$ methanol. Symbols are the same as in Figure 2.
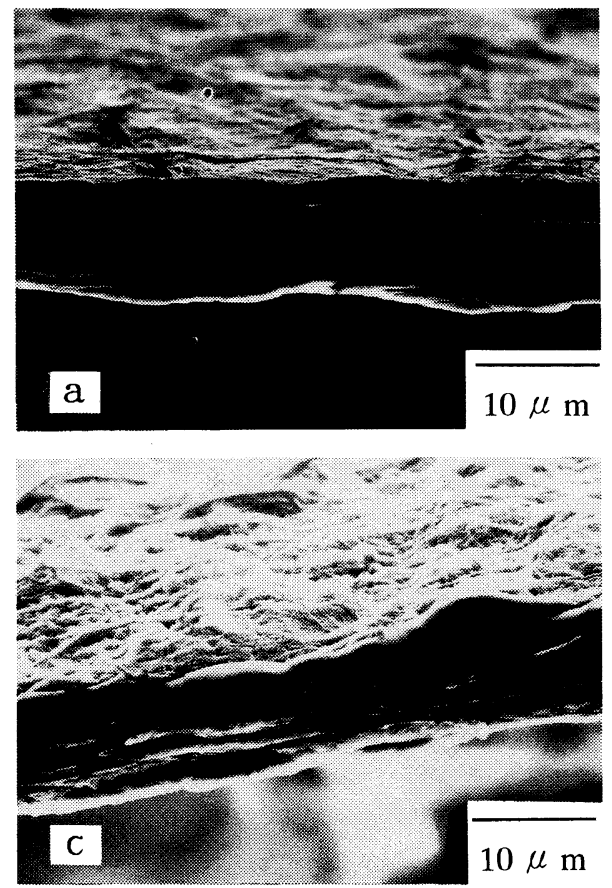

Figure 6. Scanning electron micrographs of cross sections of $\mathrm{PPy} / \mathrm{PE}$ films prepared by $\mathrm{FeCl}_{3}$-methanol. Polymerization time $4 \mathrm{~h}$, polymerization temperature (a) $0^{\circ} \mathrm{C}$, (b) $10^{\circ} \mathrm{C}$, (c) $25^{\circ} \mathrm{C}$, and (d) $40^{\circ} \mathrm{C}$. much higher intrinsic conductivity compared to PPy formed at higher temperatures. PPy obtained by oxidative polymerization of pyrrole may contain linkages at the 3-position of pyrrole, ${ }^{22}$ and furthermore, in some cases carbonyl groups were detected in PPy. ${ }^{23}$ These would cause reduction of effective length of conjugated double bonds essential for conductivity. The present results on the polym-

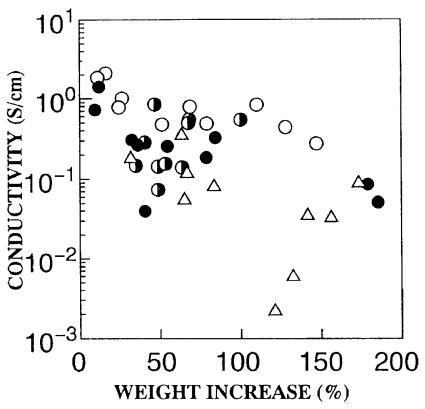

Figure 5. Plots of conductivity against weight increase of PPy/PE films prepared by $\mathrm{Fe}\left(\mathrm{ClO}_{4}\right)_{3}$-water-ethanol. Symbols are the same as in Figure 2.
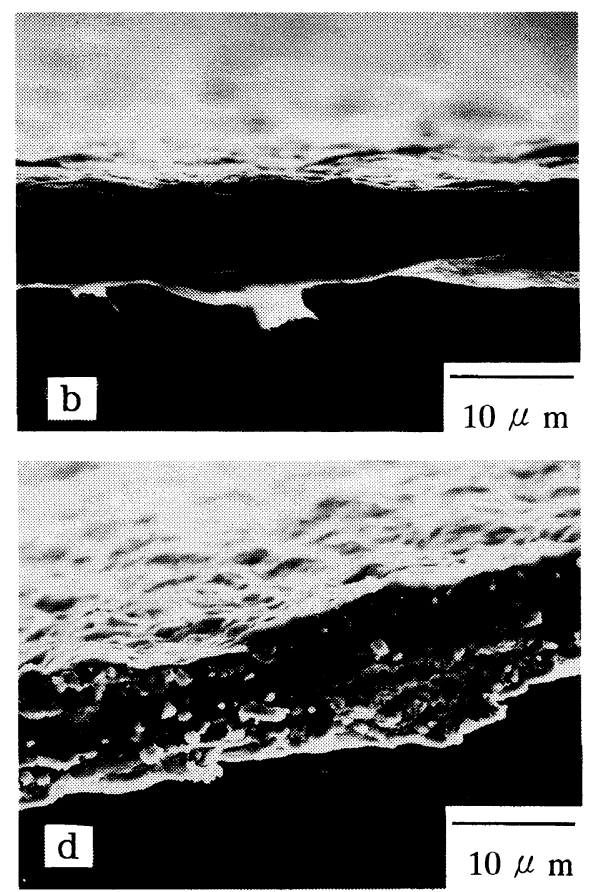
Table I. Conductivity of the films

\begin{tabular}{|c|c|c|c|}
\hline \multirow{2}{*}{ Film } & \multirow{2}{*}{$\begin{array}{c}\text { Polymeri- } \\
\text { zation } \\
\text { temp } /{ }^{\circ} \mathrm{C}\end{array}$} & \multicolumn{2}{|c|}{ Conductivity $/ \mathrm{S} \mathrm{cm}^{-1}$} \\
\hline & & $\begin{array}{l}\text { across } \\
\text { the film }\end{array}$ & $\begin{array}{l}\text { along } \\
\text { the film }\end{array}$ \\
\hline \multirow[t]{4}{*}{$\mathrm{PPy} / \mathrm{PE}^{\mathrm{a}}$} & 0 & 0.0052 & 10.9 \\
\hline & 10 & 0.0023 & 8.3 \\
\hline & 25 & 0.0071 & 2.7 \\
\hline & 40 & 0.0018 & 0.81 \\
\hline$P P y^{b}$ & r.t. & 0.053 & 10.7 \\
\hline
\end{tabular}

a Prepared by $\mathrm{FeCl}_{3}$-methanol for $4 \mathrm{~h}$.

b Prepared by vapor-phase polymerization at the surface of aqueous $\mathrm{FeCl}_{3}(3.0 \mathrm{M})$ for $24 \mathrm{~h}$.

erization temperature may be indicative of the suppression of side reactions at low temperatures.

Scanning electron micrographs (SEM) of cross sections of composite films indicate that film thickness was not so much changed with polymerization temperature (Figure 6). It can be seen that at 0 or $10^{\circ} \mathrm{C}, \mathrm{PPy}$ was formed only on the surface of PE films, whereas at higher temperatures, polymerization of pyrrole occurred in the micro pores of the PE films. However, conductivity across the PPy/PE films was not so much affected by the polymerization temperature as conductivity along the surface of the films (Table I). This suggests that only small numbers of conductive paths were formed across the films, as illustrated by Figure 7 , probably because of the limited diffusion of pyrrole monomer into the film during the polymerization.

Effects of Oxidation Potential of the Oxidant Solutions

As described in EXPERIMENTAL, PE films were dipped into organic solutions of $\mathrm{FeCl}_{3}$ and dried in the air at room temperature piror to the polymerization of pyrrole. Therefore, it was expected that some of the solvent remained in the film and formed a complex with $\mathrm{FeCl}_{3}$. It may be reasonably assumed that the oxidation potential of $\mathrm{FeCl}_{3}$ is a strong function of the coordination

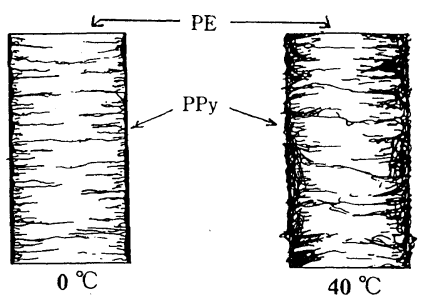

Figure 7. Schematic illustration of cross section of $\mathrm{PPy} / \mathrm{PE}$ films.

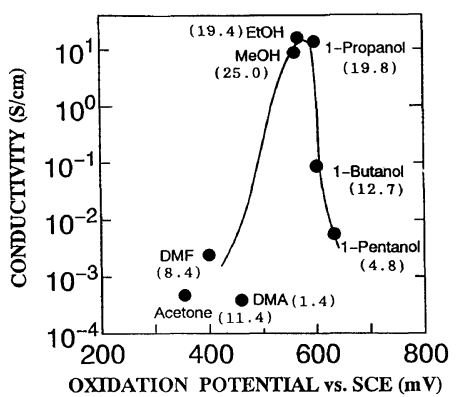

Figure 8. Effects of oxidation potential of $\mathrm{FeCl}_{3}$ solutions on $\mathrm{PPy} / \mathrm{PE}$ film conductivity. Polymerization was carried out at $0^{\circ} \mathrm{C}$ for $4 \mathrm{~h}$. Weight increase (\%) of the films is shown in parentheses.

properties of the solvents, and therefore, it was expected that the nature of the organic solvent would strongly affect the conductivity of the $\mathrm{PPy} / \mathrm{PE}$ composite films. Actually, the conductivity of PPy is significantly affected by the oxidation potential for both chemical ${ }^{24}$ and electrochemical $^{25}$ polymerization of pyrrole in solution.

A plot of the conductivity of PPy/PE composites against the oxidation potential of $\mathrm{FeCl}_{3}$ solutions is shown in Figure 8. It can be seen that the films show variation of as much as four orders of magnitude in conductivity by switching from one solvent to another. Short chain alcohols were the best solvents for the conductivity of the composite films. The oxidation potential of these $\mathrm{FeCl}_{3}$ solutions ranged from 550 to $600 \mathrm{mV} v s$. SCE, which is close to the reported optimum potential for solution polymerization of pyrrole. ${ }^{24,25}$ The results suggest that pyrrole is polymerized by $\mathrm{Fe}(\mathrm{III})$ ions complexed with organic solvents. 
It seems that the strong coordination of a solvent to $\mathrm{FeCl}_{3}$ is unfavorable for the conductivity of composite films as shown for DMF, DMA, or acetone (Figure 8). A stable complex, iron acetyl acetonate $\mathrm{Fe}\left(\mathrm{CH}_{3} \mathrm{COCH}\right.$ $\left.\mathrm{COCH}_{3}\right)_{3}$ could not polymerize pyrrole. Interestingly, conductivity was also strongly affected by the carbon number of alcohols. In spite of small differences in the oxidation potentials of alcoholic solutions of $\mathrm{FeCl}_{3}$, the conductivity of $\mathrm{PPy} / \mathrm{PE}$ films sharply dropped in going from short chain alcohols to longer ones such as 1-butanol or 1-pentanol as solvents. This may be due to steric effects of alcohols on the polymerization of pyrrole.

In contrast to the effects of polymerization temperature, the conductivity of films obtained with different $\mathrm{FeCl}_{3}$ solutions increased with increase of the weight of composite films (Figure 8). This suggests that change in conductivity in Figure 8 is, at least partly, the consequence of change in the amount of PPy in the films. Since the amount of residual solvent in the film during polymerization was not determined, it is difficult to draw any definite conclusion on the effects of solvent. However, these results indicate that, similar to PPy obtained by solution polymerization as reported in the literature, the conductivity of $\mathrm{PPy} / \mathrm{PE}$ composites can be controlled by selection of the solvent for the oxidant.

\section{Mechanical Properties of PPy/PE Composite Films}

Compared to the large number of reports on electrical properties, relatively few reports describe the mechanical properties of PPy or its composite materials. ${ }^{26,27}$ The mechanical properties of a $\mathrm{PPy} / \mathrm{PE}$ composite film were measured and the results are listed in Table II along with reported results on PPy and PPy/PVC prepared by an electrochemical method. ${ }^{26} \mathrm{PPy} / \mathrm{PE}$ composite film has higher tensile strength than original $\mathrm{PE}$ and also than PPy or PPy/PVC composite. The elongation of $\mathrm{PPy} / \mathrm{PE}$ film is much higher than that
Table II. Mechanical properties of PPy and composites

\begin{tabular}{|c|c|c|c|}
\hline \multirow{2}{*}{ Material } & $\begin{array}{l}\text { Tensile } \\
\text { strength }\end{array}$ & $\begin{array}{c}\text { Elongation } \\
\text { at break }\end{array}$ & $\begin{array}{l}\text { Young's } \\
\text { modulus }\end{array}$ \\
\hline & $\mathrm{MPa}$ & $\%$ & $\mathrm{MPa}$ \\
\hline PE & 67.0 & 215 & 160 \\
\hline $\mathrm{PPy} / \mathrm{PE}^{\mathrm{a}}$ & 83.7 & 126 & 236 \\
\hline $\mathrm{PPy}^{\mathrm{b}}$ & 46.3 & 7 & 862 \\
\hline $\mathrm{PPy} / \mathrm{PVC}^{\mathrm{b}}$ & 7.6 & 21 & 447 \\
\hline
\end{tabular}

a Prepared by $\mathrm{FeCl}_{3}$-ethanol at $0^{\circ} \mathrm{C}$ for $4 \mathrm{~h}$.

b Ref 26.

of PPy film. The mechanical properties of PPy can thus be improved by PE, and this method is useful for the production of conductive polymer films with excellent mechanical properties.

Acknowledgments. The authors thank Mitsubishi Kasei Co., Ltd. for the porous polyethylene films. Thanks are also due to INOAC Technical Center for measuring of mechanical properties of the composite films.

\section{REFERENCES}

1. O. Niwa and T. Tamamura, J. Chem. Soc. Chem. Commun., 817 (1984).

2. M. De Paoli, R. J. Waltman, A. F. Diaz, and J. Bargon, J. Chem. Soc. Chem. Commun., 1015(1984).

3. T. T. Wang, S. Tasaka, R. S. Hutton, and P. Y. Lu, J. Chem. Soc. Chem. Commun., 1343 (1985).

4. K. Uosaki, K. Okazaki, and H. Kita, J. Polym. Sci., Polym. Chem. Ed., 28, 399 (1990).

5. T. Ueno, H.-D. Arntz, S. Flesch, and J. Bargon, $J$. Macromol. Sci.-Chem., A25, 1557 (1988).

6. M. Nakata and H. Kise, Polym. J., 25, 91 (1993).

7. T. Ojio and S. Miyata, Polym. J., 18, 95 (1986).

8. A. Pron, W. Fabianowski, and C. Buorowski, Synth. Met., 18, 49 (1987).

9. F. Jousse and L. Olmedo, Synth. Met., 41-43, 385 (1991).

10. F. He, M. Omoto, T. Yamamoto, and H. Kise, Kobunshi Ronbunshuu (Jpn. J. Polym. Sci. Technol.), 50, 665 (1993).

11. N. V. Bhat and E. Sundaresan, J. Appl. Polym. Sci., 38, 1173 (1989).

12. Y.-H. Park and M.-H. Han, J. Appl. Polym. Sci., 45, 1973 (1992). 
13. F. He, M. Omoto, T. Yamamoto, and H. Kise, Nippon Kagaku Kaishi (J. Chem. Soc. Jpn, Chem. Ind. Chem.), 296 (1993).

14. B. Tieke and W. Gabriel, Polymer, 31, 20 (1990).

15. T. H. Chao and J. March, J. Polym. Sci., A, Polym. Chem., 26, 743 (1988).

16. H. Masuda, S. Tanaka, and K. Kaeriyama, J. Polym. Sci., Polym. Chem. Ed., 28, 1831 (1990).

17. J.-Y. Jin, T. Ando, N. Teramae, and H. Haraguchi, Bunseki Kagaku, 40, 799 (1991).

18. K. G. Neoh, T. C. Tan, and E. T. Kang, Polymer, 29, 553 (1988).

19. M. Sato, K. Kaneto, and K. Yoshino, Synth. Met., 14, 289 (1986).

20. M. Takakubo, Synth. Met., 18, 53 (1987).

21. M. Nakata, M. Taga, and H. Kise, Polym. J., 24,
437 (1992).

22. K. Tanaka, T. Shichiri, and T. Yamabe, Synth. Met., 14, 271 (1986).

23. O. Nishikawa and H. Kato, J. Chem. Phys., 85, 6758 (1986).

24. S. Machida, S. Miyata, and A. Techagumpuch, Synth. Met., 31, 311 (1989).

25. M. Satoh, K. Kaneto, and K. Yoshino, Synth. Met., 14, 289 (1986).

26. M.-A. De Paoli, R. J. Waltaman, A. F. Diaz, and J. Bargon, J. Polym. Sci., Polym. Chem. Ed., 23, 1687 (1985).

27. K. Yoshino, M. Tabata, K. Kaneto, and T. Osawa, Nippon Kagaku Kaishi (J. Chem. Soc. Jpn. Chem. Ind. Chem.), 342 (1986). 